\title{
NOx formation of swirl burner under air-staged combustion with flue gas recycle
}

\author{
Jinyan Yuan ${ }^{l}$, Mingming Wang ${ }^{l}$, Jihua Li ${ }^{l}$, Yuyu Lin ${ }^{l}$, Xiangyong Huang ${ }^{l}$, Mingyan Gu ${ }^{l, *}$ \\ ${ }^{1}$ School of Energy and Environment, Anhui University of Technology, Ma'anshan 243002, Anhui, China
}

\begin{abstract}
Air-staged and flue gas recycle (FGC) combustion are important technologies to reduce $\mathrm{NO}_{\mathrm{x}}$ emissions. This study explores $\mathrm{FGC}$ ratios on the $\mathrm{NO}_{\mathrm{x}}$ formation in the primary combustion zone under airstaged combustion for a HT-NR3 swirl burner at different air excess coefficients. The coal combustion characteristics including gas velocity, temperature, gas components and $\mathrm{NO}_{\mathrm{x}}$ emission under different FGC ratios were analyzed. The results show that higher the FGC ratio will larger the gas temperature decrease and lower the $\mathrm{NO}_{\mathrm{x}}$ emission. Combined FGC technology with lower air excess coefficients technology, the $\mathrm{NO}_{\mathrm{x}}$ emission at outlet of furnace will be further reduced. When the air consumption excess coefficient is 0.8 with FGC ratio $20 \%$, the $\mathrm{NO}_{\mathrm{x}}$ concentration at the furnace outlet will decrease from $208 \mathrm{ppm}$ to $138 \mathrm{ppm}$, lower $33.6 \%$.
\end{abstract}

\section{Introduction}

HT-NR3 low-nitrogen swirl burner ${ }^{[1-4]}$ and flue gas recycle technology ${ }^{[5-8]}$ are both widely used to reduce $\mathrm{NO}_{x}$ emission. $\mathrm{Hu}^{[9]}$ numerically simulated the combustion process and $\mathrm{NO}_{\mathrm{x}}$ emission characteristics of a tangentially fired boiler, the calculation results showed that, with flue gas recycle, a lower average temperature and maximum temperature in the furnace will be obtained. Wang et al. ${ }^{[10]}$ studied coal combustion under different cycle rates by numerical simulation, the results show that the combustion temperature and ignition position of pulverized coal are affected by the cycle rate. $\mathrm{Li}^{[11]}$ conducted a study on a 30 $\mathrm{t} / \mathrm{h}$ high-efficiency pulverized coal double-cylinder chamber fired industrial boiler, and the results showed that with the increase of the $\mathrm{FGC}$ ratio, the $\mathrm{NO}_{\mathrm{x}}$ reduction is $17 \%$.

This study explores FGC ratios on the NOx formation in the primary combustion zone under air-staged combustion for a HT-NR3 swirl burner, the effect of different air excess coefficients on the NOx emission also investigate to further understand the co-effect of FGC ratio and air excess coefficients on the NOx emission

\section{Numerical model}

\subsection{Mathematical model}

In this paper, the commercial software Fluent is used to numerically simulate the combustion, fluid and particle flow, heat and mass transfer of a HT-NR3 swirl burner. The non-premixed combustion model is used to simulate gasphase turbulent combustion, and the $\beta$ probability density function (PDF) is used to study the interaction between turbulence and chemical reactions. The modified Realizable k- $\varepsilon$ two equation turbulence model is used to simulate turbulent flow, and the radiation model is the P-1 model. The volatile combustion process is simulated by the CPD model, the turbulent combustion uses the finite rate chemical/vortex dissipation model, and the coal char combustion uses the diffusion kinetic model. The particle movement adopts the particle random trajectory model, and the average particle size of coal powder is $45 \mu \mathrm{m}$. In the $\mathrm{NO}_{\mathrm{x}}$ calculation, only fuel nitrogen oxides and thermal nitrogen oxides are considered, and rapid nitrogen oxides are ignored. All the nitrogen in the volatile matter is directly converted to $\mathrm{HCN}$ and $\mathrm{NH}_{3}$, part of it is converted to $\mathrm{NO}$, and the nitrogen in the char is directly converted to NO.

\subsection{Simulation zone}

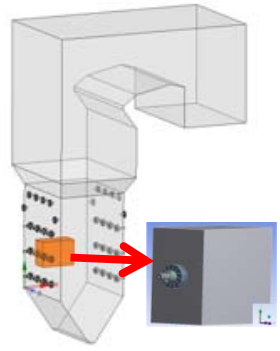

Fig. 1. Calculation model

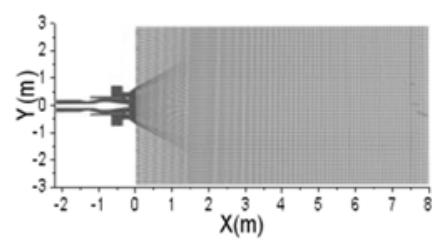

Fig.2. Mesh
The simulation object is selected from a $1000 \mathrm{MW}$ coal boiler as shown in Figure 1. HT-NR3 burner is mainly composed of primary air, secondary air, tertiary air, starter oil gun and ignition oil gun. The primary air duct is equipped with concentrator to form coal dense phase and

* Corresponding author: gumy@ahut.edu.cn 
dilute phase respectively. The primary air outlet is equipped with a flame stabilizing ring to enhance the ignition of the pulverized coal air flow. In the HT-NR3 burner, the primary air and the secondary air are no swirling flows, and the tertiary air is swirling flow. Twelve swirling blades are arranged in the tertiary air channel, and the angle of the swirling blades is $25^{\circ}$. The mesh is shown in Figure 2.

\section{Simulation conditions}

The working conditions of three FGC ratios are simulated, as shown in Table 1. The air excess coefficients of pulverized coal combustion are 1.2, and three air excess coefficients for the main combustion zone are $0.8,0.9$ and 1.0 respectively.

Table 1. Calculation cases

\begin{tabular}{cc}
\hline case & flue gas recycle ratio \\
\hline 1 & 0 \\
2 & 0.1 \\
3 & 0.2 \\
\hline
\end{tabular}

The inlet parameters are shown in Table 2, and the coal composition is shown in Table 3.

Table 2. Inlet parameter

\begin{tabular}{cccc}
\hline & $\begin{array}{c}\text { primary } \\
\text { air }\end{array}$ & $\begin{array}{c}\text { Secondary } \\
\text { air }\end{array}$ & Third air \\
\hline Air temperature $/ \mathrm{K}$ & 350 & 614 & 614 \\
Air flow ratio & 0.33 & 0.11 & 0.56 \\
Coal flowrate $/ \mathrm{kg} / \mathrm{s}$ & & 1.58 & \\
$\mathrm{Q}_{\mathrm{d}} / \mathrm{kJ} / \mathrm{kg}$ & & 23442 & \\
\hline
\end{tabular}

Table 3. Coal proximate and ultimate analyses

\begin{tabular}{cc}
\hline $\mathrm{M}_{\mathrm{t}} / \%$ & 15.55 \\
$\mathrm{~A}_{\mathrm{ar}} / \%$ & 8.8 \\
$\mathrm{~V}_{\mathrm{dar}} / \%$ & 34.73 \\
$\mathrm{C}_{\mathrm{ar}} / \%$ & 61.7 \\
$\mathrm{H}_{\mathrm{ar}} / \%$ & 3.67 \\
$\mathrm{O}_{\mathrm{ar}} / \%$ & 8.56 \\
$\mathrm{~N}_{\mathrm{ar}} / \%$ & 1.12 \\
$\mathrm{~S}_{\mathrm{ar}} / \%$ & 0.6 \\
\hline
\end{tabular}

\section{Simulation results and analysis}

\subsection{Velocity distribution}

Figure 3 shows the axial velocity distribution on the plane passing through the central axis under different FGC ratios. It can be seen that an annular recirculation zone is formed. The tertiary air enters the combustion chamber through tangential rotation, forming an annular recycle zone near the inlet of the furnace. With the increase of the FGC ratio, more flue gas enters the furnace which results in increasing of gas velocity.
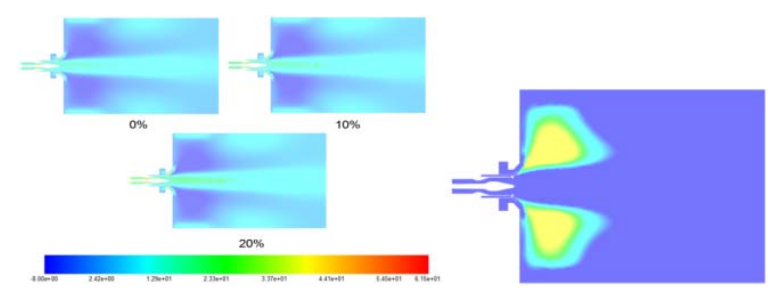

Fig. 3. Axial velocity distribution

\subsection{Gas temperature distribution}

Figure 4 shows the gas temperature distribution. It can be seen that the temperature in the center zone of the furnace is lower, while the gas temperature around the center flow is higher. This is because pulverized coal with a lower temperature absorbs a lot of heat after entering the furnace and on the other hand, the burning of volatile matter increases the gas temperature. With FGC ratio increasing, the gas temperature decreases. For the case without flue gas recycle, the peak temperature of the flame in the furnace is $2000 \mathrm{~K}$; when the flue gas recycle rate is $10 \%$, the temperature peak decreases to $1900 \mathrm{~K}$; when the flue gas recycle rate increases to $20 \%$, the flame peak temperature decreases to $1775 \mathrm{k}$. The higher the flue gas recycle rate is, the lower the combustion temperature which results in a lower thermal $\mathrm{NO}_{\mathrm{x}}$ formation.

Figure 5 shows the temperature distribution along the radial direction at different axial positions. It can be seen that the temperature trends for different FGC ratios are similar with different highest temperatures at the same position. When $\mathrm{x}=2.5 \mathrm{~m}$, the highest temperature is $1900 \mathrm{~K}$, $1800 \mathrm{~K}$ and $1700 \mathrm{~K}$ respectively. The high-temperature flue gas recirculation increases the gas temperature of the recirculation zone which helps to heat the pulverized coal particles, causing them to ignite in advance and further increase the temperature in the recirculation zone. The temperature near the center zone of the furnace is relatively low because of the high concentration of pulverized coal in the center, which absorbs a lot of heat and lower the gas temperature. At $\mathrm{x}=8 \mathrm{~m}$ position, the gas temperatures around the center zone for different flue gas recycle ratio increase.

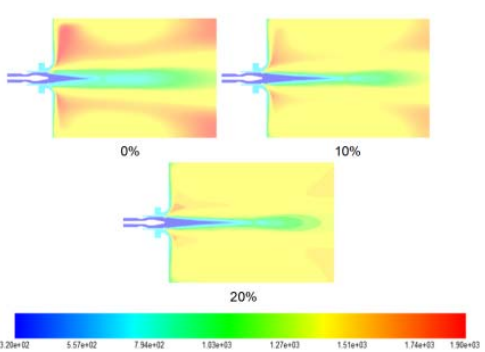

Fig. 4. Temperature distribution

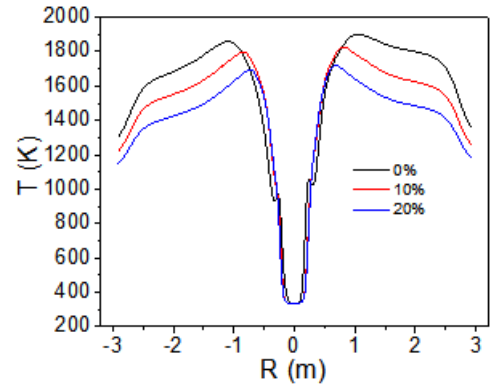




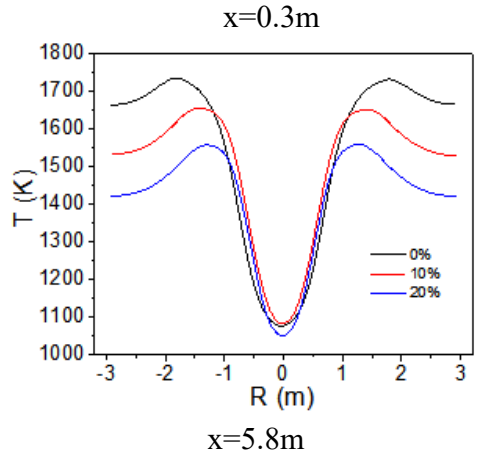

Fig.5. Temperature distribution along the radial direction at different positions

\subsection{Gas compositions}

Figure 6 shows the $\mathrm{O}_{2}$ and $\mathrm{CO}$ concentrations distributions along radial at different axial positions. It can be seen that at $\mathrm{x}=2.5 \mathrm{~m}$, the oxygen concentration in the recirculation zone is lower and the $\mathrm{CO}$ concentration is higher. As the FGC ratio increases, the $\mathrm{CO}$ concentration in the recirculation zone decreases. At the $\mathrm{x}=8 \mathrm{~m}$, the temperature increases, the oxygen concentration decreases, and the $\mathrm{CO}$ concentration increases. For the three FGC ratios, the maximum outlet $\mathrm{CO}$ concentration is $0.17,0.144$ and 0.11 , respectively. It can be seen that the use of FGC technology can effectively reduce the $\mathrm{CO}$ concentration, and the effect is more obvious when the flue gas recycle ratio is $20 \%$.

Figure 7 shows the $\mathrm{NO}_{\mathrm{x}}$ concentration in the recirculation zone and at the furnace outlet with different FGC ratios. When the FGC rate is $0 \%, 10 \%$, and $20 \%$, the maximum $\mathrm{NO}_{\mathrm{x}}$ concentration in the recirculation zone is $375 \mathrm{ppm}, 160 \mathrm{ppm}$ and $155 \mathrm{ppm}$; the maximum outlet $\mathrm{NO}_{\mathrm{x}}$ concentration is $280 \mathrm{ppm}, 180 \mathrm{ppm}$ and $175 \mathrm{ppm}$ respectively.

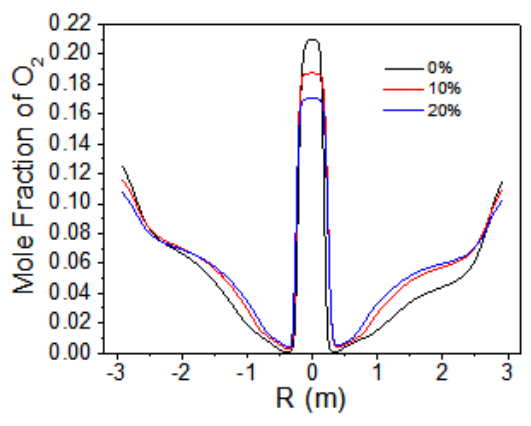

$\mathrm{x}=0.3 \mathrm{~m}$

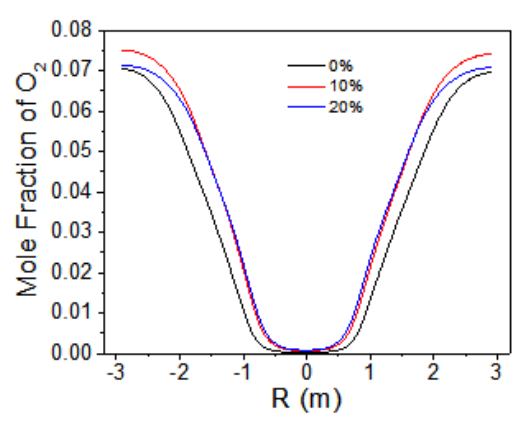

$\mathrm{x}=5.8 \mathrm{~m}$

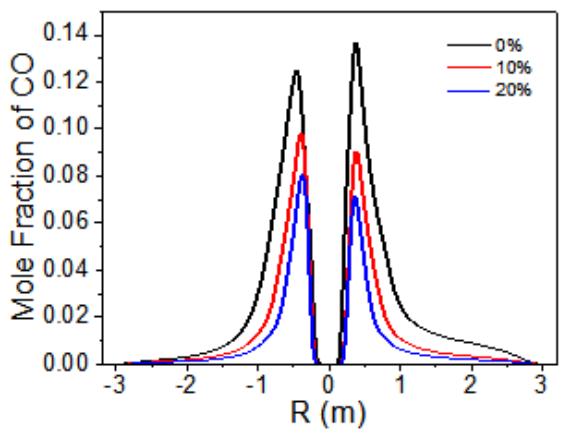

$\mathrm{x}=0.3 \mathrm{~m}$

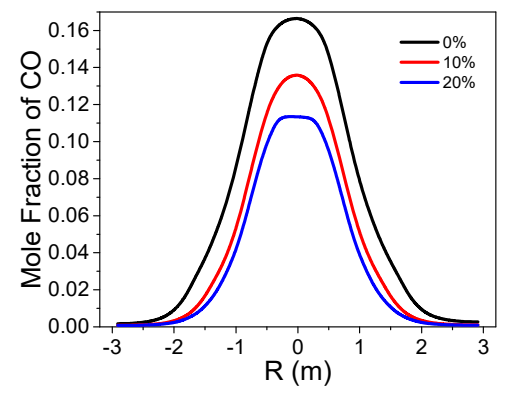

$\mathrm{x}=5.8 \mathrm{~m}$

Fig.6. $\mathrm{O}_{2}$ and $\mathrm{CO}$ concentration along the radial distribution
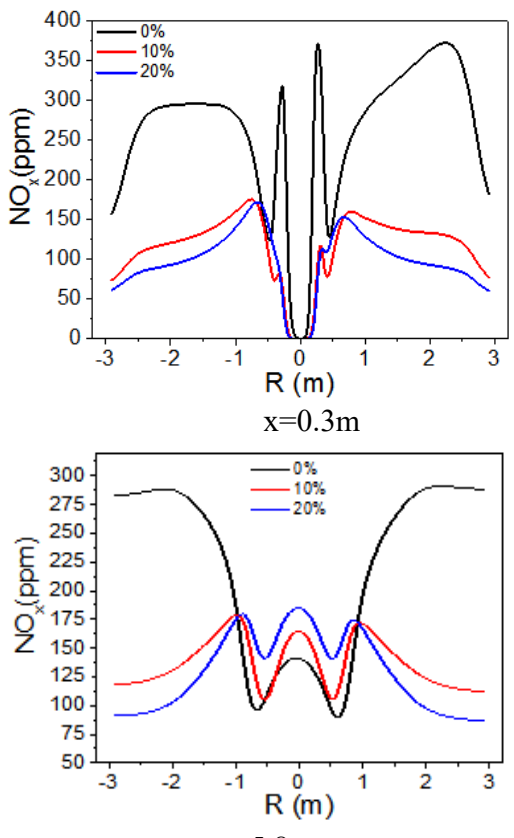

$\mathrm{x}=5.8 \mathrm{~m}$

Fig.7. $\mathrm{NO}_{\mathrm{x}}$ concentration distribution along the radial direction

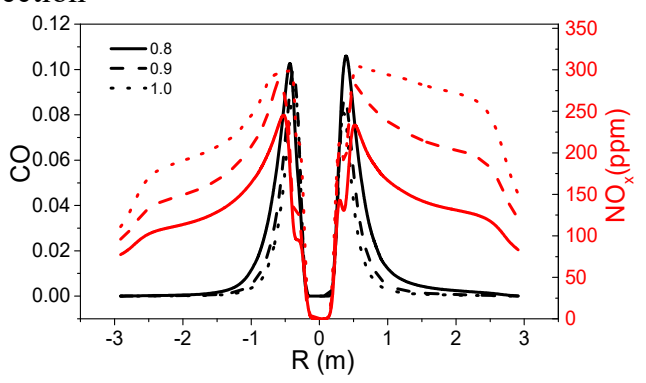

(a) $\mathrm{FGC}$ ratio $0 \%$ 


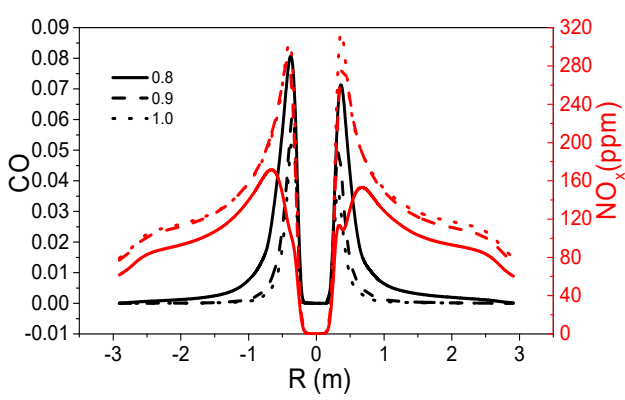

(b) FGC ratio $10 \%$

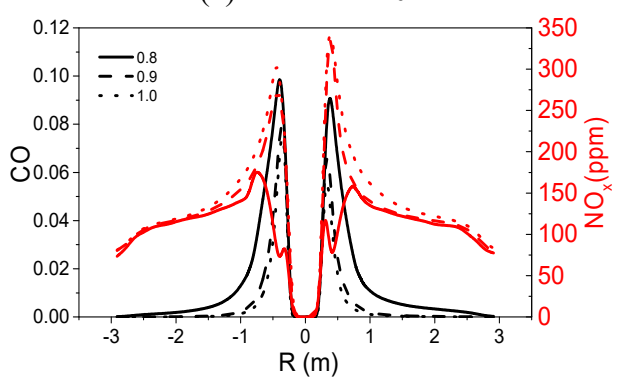

(c)FGC ratio $20 \%$

Fig.8. Changes in $\mathrm{CO}$ and $\mathrm{NO}_{\mathrm{x}}$ concentrations at $\mathrm{X}=2.5 \mathrm{~m}$ under different air consumption coefficients and flue gas recycle ratios

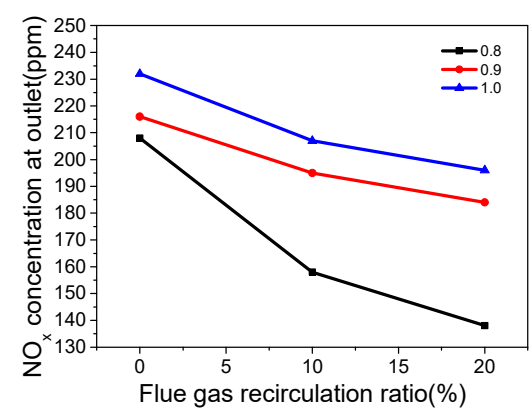

Fig.9. $\mathrm{NO}_{\mathrm{x}}$ concentration at furnace outlet

Figure 8 shows the changes in $\mathrm{CO}$ and $\mathrm{NO}_{\mathrm{x}}$ concentrations under different air excess coefficients and FGC ratios at $x=2.5 \mathrm{~m}$. It can be seen that the $\mathrm{CO}$ and $\mathrm{NO}_{\mathrm{x}}$ concentrations under different excess coefficients are greatly different. As the air excess coefficient increases, the concentration of $\mathrm{CO}$ becomes lower, and the concentration of $\mathrm{NO}_{\mathrm{x}}$ becomes higher.

Figure 9 shows the NOx concentration at the furnace outlet with three FGC ratios under different air excess coefficients. It can be seen that with the combination of FGC and lower air excess coefficients, the $\mathrm{NO}_{\mathrm{x}}$ concentrations will result in a great decrease in $\mathrm{NO}_{\mathrm{x}}$ emission. With the increase of the $\mathrm{FGC}$ ratio, the $\mathrm{NO}_{\mathrm{x}}$ concentration decreases. When the FGC ratio is 0 and $20 \%$ at the air excess coefficients 0.8 , the $\mathrm{NO}_{\mathrm{x}}$ concentration is reduced from 208ppm to $138 \mathrm{ppm}$; when the air excess coefficients is 0.9 , the $\mathrm{NO}_{\mathrm{x}}$ concentration is reduced from $216 \mathrm{ppm}$ to $184 \mathrm{ppm}$; when the air excess coefficients is 1.0 , the $\mathrm{NO}_{\mathrm{x}}$ concentration was reduced from $232 \mathrm{ppm}$ to $196 \mathrm{ppm}$.

\section{Conclusion}

The pulverized coal combustion and $\mathrm{NO}_{\mathrm{x}}$ formation characteristics in a main combustion zone with different air excess coefficients for air-staged swirl burner with different FGC ratios were simulated.

(1) An annular recirculation zone is formed near the inlet of the furnace which results in a higher gas temperature zone, a lower oxygen concentration and a higher $\mathrm{NO}_{\mathrm{x}}$ concentration zone.

(2) The higher the FGC ratio, the larger the gas temperature decrease and a lower $\mathrm{NO}_{\mathrm{x}}$ emission can be obtained. When the FGC rate is $0 \%, 10 \%$, and $20 \%$, the maximum $\mathrm{NO}_{\mathrm{x}}$ concentration in the recirculation zone is $375 \mathrm{ppm}, 160 \mathrm{ppm}$ and $155 \mathrm{ppm}$, respectively.

(3) Combined FGC technology with lower air excess coefficients technology, the $\mathrm{NO}_{\mathrm{x}}$ emission at outlet of furnace will be further reduced. When the air consumption excess coefficient is 0.8 with FGC ratio $20 \%$, the $\mathrm{NO}_{\mathrm{x}}$ concentration at the furnace outlet will decrease from 208ppm to $138 \mathrm{ppm}$, lower $33.6 \%$.

\section{Acknowledgement}

This work was supported by the National Key Research and Development Program of China (2017YFB0601805)

\section{References}

1. Cheng Huaizhi, Wen Lei, Song Zhengchang. Journal of Power Engineering, 35(009):704-708(2015).

2. Dang Lingui, Chen Guoxi, Wang Chunyu, et al. Chinese Journal of Power Engineering.

3. Zhou H, Yang Y, Dong $\mathrm{K}$, et al. Fuel, 134(oct.15):595-602(2014).

4. Li Chaoliang. Hubei Electric Power, 41(5): 2531(2017).

5. $\mathrm{Hu} \mathrm{Y}, \mathrm{Yan}$ J. International Journal of Greenhouse Gas Control, 17:473-480(2013).

6. Chen Songlin, Fan Junjie, Zhang Zhongxiao, et al. Power Station System Engineering, 2019.

7. Li Gaoliang, Wang Naiji, Xiao Cuiwei, et al. Clean Coal Technology, 134-137-142(2015.02).

8. Li Z, Liu X, Shao Y, et al. Journal of Thermal Science,29(2) (2020).

9. Hu Manyin, Qiao Huan, Du Xin, et al. Journal of North China Electric Power University (Natural Science Edition), 77-82 (2007) (06).

10. Wang Peng, Guo Junjun, Wu Haibo, et al. Thermal Power Generation, 048(004): 90-95(2019).

11. Li Gaoliang, Wang Naiji, Xiao Cuiwei, et al. Clean Coal Technology, 34-137-142(2015) (02). 